\title{
Advancing Network Analysis of Ghinese Businesses: Commentary on Burt and Burzynska
}

\author{
Nan Lin \\ Duke University, USA
}

\section{INTRODUGTION}

Burt and Burzynska (2017) have produced a very significant and innovative study on social networks among Chinese entrepreneurs. As the authors claim, this may be an exceptional dataset with certain unique features. It is a comparative study between Chinese and American entrepreneurs. While the American data is rather limited in scope, it does provide valuable theoretical and measurement information by which to examine possible similarities and differences of the private enterprises and entrepreneurs in these two societies. Second, it examines two general network principles, namely the association between brokerage and success, and between closure and trust. In general, the study affirms comparable results in the two societies, though somewhat different measurements require cautious interpretation. Third, the authors explore two innovative notions worthy of our attention. They employ events as the frames on which social ties (contacts) were generated (Table Al). This turns out to be very fruitful. For example, the founding event provided interesting social network information, more so than current and other events. The event-name generators reveal the timerelated dynamics of network stability and changes, and alert us to possible underestimation of network effects if only the current event or the present time is examined. Finally, the authors attempt possible network measures for the notion of guanxi. This exploration sets the initial stage for more rigorous measures of guanxi in future studies of entrepreneurs in China and other societies.

The authors carefully lead the readers through the theory, measures, and data analyses. Those who are novices in theory and measurement can thus gain knowledge about the power and operations of social networks, while those who are learned scholars in this field can appreciate how social networks operate in the Chinese business community. 
On these grounds, I consider it a rich, groundbreaking benchmark study on Chinese entrepreneurship.

The following are some thoughts evoked from reading this stimulating report. They pertain to (1) the role of the state and politics in the development and operation of private enterprises in China, (2) the need to consolidate and clarify certain key concepts and measurements, (3) the need for external validity of closure and trust, and (4) further development of the concept and measurement of guanxi.

\section{THE STATE IN THE PRIVATE SEGTOR}

The study sample came from Shanghai, four cities in Jiangsu, and five cities in Zhejiang. These were good choices for sampling private enterprises in China since they are three of the four regions in China with the largest concentrations of private enterprises in China, the other being Guangdong, according to the 2016 China Private Enterprise Survey Report (CPESR). In terms of employment, capital, and assets, they probably represent one-third of all private enterprises in China. However, these are also regions where state-owned and collective enterprises once dominated. Over a period of twenty years or so, many of these SOEs and collectives have transformed themselves into private enterprises. Elements of the state and collective institutions continue to be embedded. For example, among the private enterprise owners surveyed in the 2016 study (CPESR), about 30 percent (29.9 percent) are party members. This figure represents a dramatic increase over the years (i.e., it was 13.1 percent in 1993, 17.1 percent in 1995, 16.6 percent in 1997, and 19.8 percent in 1999). Due to the increased transformation of state and collective enterprises into private enterprises, the presence of the party (e.g., officers and offices) can be correspondingly expected to increase in the private sector.

It is therefore not surprising that political guanxi and social capital may be associated with obtaining important policy-related resources. For example, Lou and Tang (2009) studied 926 private enterprises sampled from ShanghaiShenzhen stock markets from 2002 to 2005. They find significant associations between political connections ${ }^{[1]}$ and access to valued industries and land-housing developments. Given that the study only reported associative relations and the term 'political background' was not further defined, the large-sample study nevertheless alerts us to explicit and latent state-collective connections and their possible effects on enterprise performance.

Similarly, Li (1995) reports a sample study of 1,440 private enterprise owners. He shows that the owners' social capital, as captured in the occupational and authority positions of their relatives and friends, make significant contributions to their entering into the private sector, obtaining resources, and developing their enterprises. Among enterprises in the top 30 percent (asset value), over half of their owners' relatives and friends were 'cadres in institutions and enterprises', and between 38 to 52 percent were 'institution and enterprise responsible persons' (Table 9). Since it was collected in 1993 the data may be dated, but given the 
evidence of the increasing presence of transformed state and collective enterprises over the last two decades, we cannot dismiss the idea that such guanxi effects have persisted in private enterprises. These trends warn us of a possible joint 'top-down' and 'bottom-up' process in the creation and operation of private enterprises, as many studies have shown. While the current leadership (i.e., Xi Jinping) has stressed the importance of separating politics and business (政商分岐), the continued insistence on the party being the core (核心) of society and Xi being the core of the party should alert all researchers of the significance of the strong embedding of economy in the political institutions in China. ${ }^{[2]}$

What should be included in such studies? At a minimum, they should distinguish enterprises with and without state-collective background or origin. Further, we need to be sensitive to the presence or absence of party officers and offices in private enterprises. We also need to know who among the trustees and directors can exercise critical authority beyond the owners and founders in the enterprise, as well as their connections to the party and state-collective institutions. Network approaches are probably the best way to obtain such information. These data should help us understand the interactive patterns between the public and 'private ${ }^{[3]}$ sectors in China, and how they provide advantages as well as detriments to private enterprises.

\section{GONGEPTUAL GOMPLEXITY AND INTEGRATION}

Central to the network measurements employed in the study are the notions of structural holes, constraints, brokerage, and closure. All these concepts were initially introduced as structural features - closure by Coleman, and structural holes, brokerage, and constraints by Burt. Closure stresses interactions among members in a group and/or the lack of interactions with outsiders. Structural holes measure the possibility of two or more groups being independent of each other. The significance of possible structural holes is further amplified by uncovering presence of a tie or ties that bridge such holes. Brokerage seems to emphasize the presence of a tie or ties that bridge holes. Constraints (i.e., absence or presence or number of third parties between ties) have been used to represent or indicate closure (see Figure 4). Thus, Burt and others employ each of these concepts to suggest closed or open networks, depending on values of their measurements and foci in the particular studies.

Further complications are introduced since these concepts have also been operationalized as individual/actor properties. They appear in analyses for individuals (e.g., entrepreneurs), as in the present study. The utility of concepts for both macro- and micro-level analyses may be beneficial in theory building. However, we must attend to the issue of epistemic correspondence of terms and propositions across the macro-micro levels. Generalization from one level to the other may or may not be valid. Readers must be cautioned as to the particular level at which measures are devised and results pertain. These conceptual and 
empirical issues regarding closure, brokerage, constraints, structural holes, and related network measures ${ }^{[4]}$ need a comprehensive articulation, and Burt is undoubtedly in a unique position to write such an essay.

\section{EXTERNAL VALIDITY}

An important feature of the present paper is the conceptual parallel associations between brokerage with business success and between closures with trust. The relationship between brokerage and business success is theoretically and operationally straightforward. Brokerage is measured by constraint and success measured by number of employees, sales, and patents; the former is perceived as a potential causal factor for the latter. They are measured independently so that their association offers external validation of the principle. On the other hand, the association between closure and trust is not so clear. Both closure and trust are network measures from the name generators. They are 'internal' properties of the network measures. It is perfectly fine to examine and analyze multiple properties in the networks; however, the potential causal path between the two is not as easily discerned. In the general network literature (e.g., Coleman, Burt) closure is seen as associating or predicting, among other concepts, group norms or behavior (e.g., cohesion, solidarity, trust). The group notion is measured independently of network closure so that its external validity in association can be assessed. The availability of tie trust in the data set avails itself as a proxy for group norms or behavior and can be seen as an internal validity of the proposition. A behavioral measure for trust or related concepts is necessary to externally validate the association so that the second principle can be validated in parallel to the first principle.

\section{GUANXI: GONGEPTUALIZATION AND MEASUREMENTS}

It is exciting to read Burt and Burzynska's examination of the notion of guanxi. Guanxi has received extensive attention from those working on Chinese society and businesses, most notably Bian, Luo, and their colleagues. However, conceptualization and measures have remained fuzzy. ${ }^{[5]}$ Burt and Burzynska adopt a clear definition of guanxi as a tie in which relative trust is high and is not dependent on structural embedding (implicating third parties). In actual analyses, they focus on three aspects of ties: (1) high trust, (2) established in events (especially significant events such as founding), and (3) stable over time (e.g., more than two years). ${ }^{[6]}$ Using these criteria, they identify the inner core of guanxi - family members of the founders, for example. This is consistent with most previous discussion and studies of guanxi. Analyses also allow them to identify critical and persistent ties used by entrepreneurs from the founding to the present. This is a major advance in the operationalization of guanxi and provides specific guides for research and measurements for identifying guanxi in network research. 
Several features stand out in this analysis. First, tie trust becomes a criterion indicator or the principal component of guanxi. Network correlates with trust validate there also being components of guanxi. Thus, critical events (Figure 4b) are validated and constraints for these events are much less relevant. This analysis strongly hints that the ties at critical events are guanxi. The message is clear and important - guanxi can be teased out in critical events for the entrepreneurs. This analysis and finding also highlight another important characteristic of guanxiexpected or actual utility in social relationships. That is, guanxi not only promotes trust and sentiment in the relationship, it also expects resource exchanges. The event-based analysis offers a partial but clear glimpse of this feature of guanxi. Thus, guanxi may best be examined (1) in a dyadic relationship, (2) in the degree of trust or sentiment, and (3) in expected or actual exchanges of resources.

We can build on Burt and Burzynska's leads to advance future conceptualization of guanxi. Two measurement approaches come to mind. One direction is to link possible event ties with transaction outcomes, in addition to trust. In examining the ties used in critical events, we could assess both the extent of sentiment or trust between ego and helper(s) but also what benefits ego expected or actually obtained through such ties. In analyzing such data we could employ both trustsentiment and benefits as criteria components, and identify network features as well as characteristics of helpers and ego-helper relationships to further identify the components of guanxi ties.

Another direction is to construct guanxi generators directly. Most Chinese seem to cognitively understand what it means. So instead of asking for names of the most valuable ties as in the event-name generators, we could ask guanxi ties used in critical events: Who was (were) the most important guanxi you used? Followup questions could then be asked (guanxi interpreters, characteristics of the guanxi tie, the actual relationship between ego and the guanxi helper) and the resources exchanged or received. I suspect that such a direct approach would yield data and information similar to those from the event-name generator. However, the guanxi generators are more direct and provide data on which further reliability and validity tests could readily be made, across different events, different generators (name generators and resource generators), and different cultures and societies. Such analyses would help shed light on the true nature of guanxi in the network contexts of Chinese society and beyond.

\section{NOTES}

[1] The measures include (1) percent of trustees (or directors) having 'political background', (2) strength of enterprise political background, (3) percent of trustees (directors) having provincial or below-provincial level 'political background', (4) owners having 'political background', and (5) owners having provincial-level or below 'political background', (6) having two or more trustees (directors) having 'political background'.

[2] See Lam (2015)

[3] In public documents and media reports, the term, min-yin 民營 (non-government owned) is often used instead of 私營 (privately owned), even though min-yin does not appear in official 
documents. Min-yin implies non-government ownership but possible government background or involvement (personnel, resources, and affiliation) in the enterprise. In general, the private sector includes all min-yin enterprises. The subtlety of the terms suggests the general awareness that a portion of the private enterprises is in fact government-associated.

[4] For example, constraint, as a structural measure, indicates the extent of group closure, and it is an alternative and perhaps more stringent measure of structural holes where no bridges are possible or considered. Or, more relaxed, constraint is a measure of group density - inter-connectivity among ties in the group. It is therefore not surprising this measure, in the study data, is highly correlated with group size (Footnote \#2) around -0.89. It means that density is inversely related to group size. At the individual level, it measures the extent to which third parties are present between two ties (e.g., ego and contact).

[5] See Bian and Ikeda (2016) for the current thinking and research on guanxi in East Asia.

[6] I would argue that sentiment (qing) is a better term than trust to characterize guanxi. See also Bian and Ikeda (2016). In the Chinese symbolic and cultural contexts, qing is widely understood and appreciated. It represents the expressive, affective and sentimental aspect in dyadic relationships. It may overlap with personal trust, but not with generalized trust. We may defer this debate elsewhere; I will proceed with the term, trust, as used by Luo and the present authors.

\section{REFERENGES}

Bian, Y., \& Ikeda, K. 2016. East Asian social networks. In R. Alhajj \& J. Rokne (Eds.), Encyclopedia of social network analysis and mining: 1-22. NYC: Springer.

Burt, R.S., \& Burzynska, K. 2017. Chinese entrepreneurs, social networks, and guanxi. Management and Organization Revieze, 13(2): doi:10.1017/mor2017.6.

Lam, W. W.-L. 2015. Chinese politics in the era of Xi Jinping. Abingdon-on-Thames: Routledge.

Li, L. L. 1995. Social capital and private entrepreneurs. Social Sciences in China, 6: 46-58 (in Chinese).

Luo, D.-L., \& Tang, Q.-Q. 2009. Political relations, social capital and policy resource attainment. The Journal of World Economy, 7: 84-96 (in Chinese). 